\title{
Femur Fracture
}

National Cancer Institute

\section{Source}

National Cancer Institute. Femur Fracture. NCI Thesaurus. Code C26774.

A traumatic or pathologic injury to the femur in which the continuity of the femur is broken. 